\title{
Identification and quantitation of cis-ketoconazole impurity by capillary zone electrophoresis-mass spectrometry
}

\author{
María Castro-Puyana ${ }^{a}$, Carmen García-Ruiz ${ }^{a}$, Alejandro Cifuentes ${ }^{b}$, \\ Antonio L. Crego ${ }^{\text {a }}$, Maria Luisa Marina ${ }^{\mathrm{a}, *}$ \\ ${ }^{a}$ Department of Analytical Chemistry, Faculty of Chemistry, University of Alcalá, Ctra. Madrid-Barcelona Km. 33.600, \\ 28871 Alcalá de Henares, Madrid, Spain \\ ${ }^{\mathrm{b}}$ Department of Food Analysis, Institute of Industrial Fermentations (CSIC), Juan de la Cierva 3, 28006 Madrid, Spain
}

Received 2 November 2005; received in revised form 3 February 2006; accepted 14 February 2006

Available online 6 March 2006

\begin{abstract}
trans-Ketoconazole was identified and quantified as impurity of cis-ketoconazole, an antifungal compound, by capillary zone electrophoresis-electrospray-mass spectrometry (CZE-ESI-MS). The chirality of this impurity was demonstrated separating their enantiomers by adding heptakis-(2,3,6-tri- $O$-methyl)- $\beta$-cyclodextrin to the separation buffer in capillary electrophoresis (CE) with UV detection. However, MS detection was hyphenated to the CE instrument for its identification. As both compounds are diastereomers, they have the same $m / z$ values and are needed to be separated prior to the MS identification. A $0.4 \mathrm{M}$ ammonium formate separation buffer at $\mathrm{pH} 3.0 \mathrm{enabled}$ the separation of the impurity from cis-ketoconazole. Under these conditions, the optimization of ESI-MS parameters (composition and flow of the sheath-liquid, drying temperature, drying gas flow, and capillary potential) was carried out to obtain the best MS sensitivity. CZE-ESI-MS optimized conditions enabled the identification of trans-ketoconazole as impurity of cis-ketoconazole. In addition, the quantitation of this impurity was achieved in different samples: cis-ketoconazole standard and three different pharmaceutical formulations (two tablets and one syrup) containing this standard. In all cases, percentages higher than 2.0 were determined for the impurity. According to ICH guidelines, these values required the identification and quantitation of any impurity in drug substances and products.
\end{abstract}

(C) 2006 Elsevier B.V. All rights reserved.

Keywords: cis-Ketoconazole; trans-Ketoconazole; CE-MS; Impurity; Pharmaceutical formulations

\section{Introduction}

An impurity is defined as any component of a drug product that is not the drug substance or an excipient in the drug product. Their detection, identification and quantitation are important aspects in the development of new drug substances and products. The ICH guidelines on impurities (topics Q3A and B in ICH Harmonised Tripartite Guideline) define certain thresholds for the content of impurities above which they should be identified and/or quantified. These thresholds have recently been revised (February 2002 and 2003) establishing $0.05-0.1 \%$ in new drug substances and $0.1-1.0 \%$ in new drug products, depending on the amount of drug substance administered per day [1-3]. In fact,

\footnotetext{
* Corresponding author. Fax: +34 918854971.

E-mail address: mluisa.marina@ uah.es (M.L. Marina).
}

an accurate analytical profile of a drug substance must fulfill the requirements of regulatory agencies with respect to toxicity and safety aspects from the initial stage of the development of a potential drug to the quality control of a marketed pharmaceutical product [4].

Although HPLC coupled with MS is the most used methodology for impurity profiling of drugs, the hyphenation of $\mathrm{CE}$ with MS presents a current interest. As indicated in a recent review [5], CE has emerged as a powerful analytical tool that can provide useful information on the chemical properties of drugs, impurities and metabolites [6,7]. One of the main characteristics of CE is its selectivity, which can be modified to achieve uniquely tailored separations in order to monitor very different drugs, impurities and/or metabolites. Often the separation is different and complementary to classical techniques such as HPLC [8]. Moreover, the characterization of new synthesized drugs as well as unknown compounds in drugs (i.e., impuri- 
ties or metabolites) constitutes a general analytical problem. In order to improve sensitivity and selectivity while increasing the information achievable by $\mathrm{CE}$, this technique can be interfaced with electrospray MS to bring about a very powerful hyphenated technique. This is because the on-line coupling of CE with electrospray ionization mass spectrometry (ESI-MS) yields a powerful method [9-12] in which CE offers high separation efficiency, while ESI-MS allows the determination of an accurate mass for a wide molecular mass range of molecules. CE can be coupled with different MS analyzers as quadrupole, ion trap (IT), time of flight (TOF), etc., IT and TOF mass spectrometers being very powerful detectors for CE-ESI-MS due to their sensitivity and speed. In addition, IT can be used for $\mathrm{MS}^{n}$ experiments, and TOF is especially useful due to its high mass resolution and the possibility of measured mass accuracy in it.

The possibilities of CE-MS for drug analysis have recently been reviewed [13]. Based on the multiple applications of $\mathrm{CE}$ in this field and the good possibilities demonstrated by CE-MS in different fields of application, it can be concluded that CE-MS can be a very useful tool to characterize drugs and investigate their impurities and/or metabolites [14].

This work is focused on the identification and determination of ketoconazole impurities. Ketoconazole, which is a chiral drug used for the treatment of fungal diseases, is clinically employed as a racemic mixture (1:1 mixture of the two enantiomers) of the cis configuration [15]. cis-Ketoconazole (1acetyl-4-[4-[[(2R,4S)-2-(2,4-dichlorophenyl)-2-(1H-imidazol1-ylmethyl)-1,3-dioxolan-4-yl]methoxy]phenyl]piperazine) possesses two chiral centers with defined configurations, and the impurity, trans-ketoconazole (1-acetyl-4-[4-[[(2R,4R)2-(2,4-dichlorophenyl)-2-(1H-imidazol-1-ylmethyl)-1,3-

dioxolan-4-yl]methoxy]phenyl]piperazine), has the same chiral configuration as cis-ketoconazole except for position 4 which changes from $\mathrm{S}$ to $\mathrm{R}$, both compounds being diastereomers (see Fig. 1). There are three other possible impurities reported by the European Pharmacopoeia (impurity II: 1-acetyl-4-[4-[[(2R,4R)2-(2,4-dichlorophenyl)-2-(1H-imidazol-1-ylmethyl)-1,3dioxolan-4-yl]methoxy]phenyl]1,2,3,4-tetrahydropiperazine, impurity III: 1-acetyl-4-[4-[[(2R,4R)-2-(2,4-dichlorophenyl)-2(1H-imidazol-1-ylmethyl)-1,3-dioxolan-4-yl]methoxy]-3[4-(4acetylpiperazin-1-yl)phenoxy]phenyl]piperazine and impurity IV: $\quad 1-[4-[[(2 \mathrm{R}, 4 \mathrm{~S})-2-(2,4-$ dichlorophenyl)-2-(1H-imidazol1-ylmethyl)-1,3-dioxolan-4-yl]methoxy]phenyl]piperazine)

[16]. As cis-ketoconazole is a chiral drug, the use of chiral conditions are necessary for the separation of their enantiomers. However, the separation of diastereomers, such as cis- and trans-ketoconazole, can be performed under achiral conditions as they have different chemical properties.

Although the determination of ketoconazole in human plasma has been successfully performed by HPLC-MS [17], the impurities of this antifungal agent have not been identified and quantified until now. With this purpose, in the present work, the main impurity of $c$ is-ketoconazole was detected and enantiomerically separated by CE with UV detection, and identified and quantified by CE-ESI-MS under achiral conditions. ESI-MS parameters were optimized in order to obtain the maximum sensitivity for the determination of trans-ketoconazole present as impurity in ketoconazole standard and in several commercial pharmaceutical formulations containing cis-ketoconazole as drug substance.

\section{Experimental}

\subsection{Chemicals}

All chemicals were of analytical grade. Formic acid and acetic acid were supplied from Riedel-Hagën (Seelze, Germany).

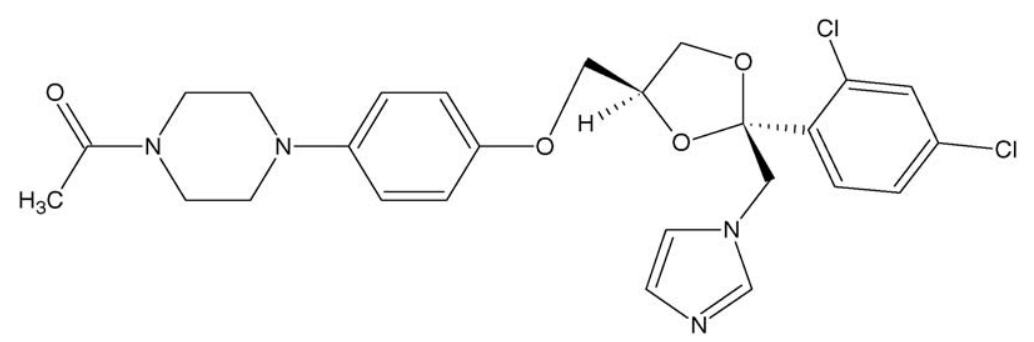

Cis-ketoconazole

$\left(\mathrm{C}_{26} \mathrm{H}_{28} \mathrm{Cl}_{2} \mathrm{~N}_{4} \mathrm{O}_{4}\right.$, and exact mass $\left.=530.1487 \mathrm{~g} / \mathrm{mol}\right)$

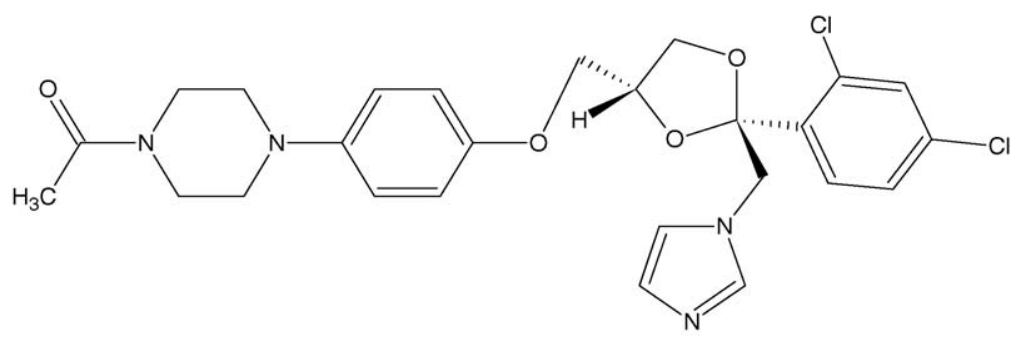

Trans-ketoconazole

$\left(\mathrm{C}_{26} \mathrm{H}_{28} \mathrm{Cl}_{2} \mathrm{~N}_{4} \mathrm{O}_{4}\right.$, and exact mass $\left.=530.1487 \mathrm{~g} / \mathrm{mol}\right)$

Fig. 1. Structures of $c i s$-ketoconazole and trans-ketoconazole with their empirical formulas and exact masses. 
Twenty-five percent ammonium solution was supplied from Merck (Darmstadt, Germany). Dimethylsulfoxide (DMSO) was purchased from Fluka (Buchs, Switzerland). Heptakis(2,3,6-tri- $O$-methyl)- $\beta$-cyclodextrin (TM- $\beta$-CD) from Sigma (St. Louis, MO, USA) was used as chiral selector. Methanol, isopropanol, and acetonitrile were purchased from Scharlau Chemie (Barcelona, Spain). Water used to prepare solutions was purified through a Milli-Q system from Millipore (Bedford, MA, USA). cis-Ketoconazole standard (drug substance) was supplied from Sigma (St. Louis, MO, USA). Different pharmaceutical formulations (drug products), tablets and syrup, were obtained from a pharmacy in Guadalajara (Spain).

\subsection{Procedures}

Buffer solutions were prepared by diluting the appropriate volume of formic acid with Milli-Q water and adjusting the $\mathrm{pH}$ to 3.0 with $25 \%$ ammonia solution before completing the volume with water to get a $0.4 \mathrm{M}$ formate buffer. Finally, background electrolytes (BGEs) containing the chiral selector were prepared by dissolving the appropriate amount of the cyclodextrin in the buffer solution ( $0.4 \mathrm{M}$ formate at $\mathrm{pH} 3.0)$.

The stock standard solution of the investigated compound (cis-ketoconazole) was prepared by dissolving it in DMSO up to a final concentration of $2 \mathrm{mg} / \mathrm{mL}$. Eight diluted solutions of cis-ketoconazole $(0.02,0.04,0.10,0.20,0.50,1.00,1.50$ and $2.00 \mathrm{mg} / \mathrm{mL}$ ) were used for calibration in the $0.02-2.00 \mathrm{mg} / \mathrm{mL}$ range. Calibration for the impurity was performed considering its percentage in the cis-ketoconazole standard. With this purpose, the five solutions of cis-ketoconazole with the highest concentrations $(0.20-2.00 \mathrm{mg} / \mathrm{mL})$ were considered.

Sample solutions of pharmaceutical formulations were prepared in a different way depending on the type of formulation. Tablets were weighed and powdered. Then, an amount of the powder obtained was weighed and dissolved in $10 \mathrm{~mL}$ DMSO to obtain a concentration of about $2 \mathrm{mg} / \mathrm{mL}$ in cis-ketoconazole (taking into account the labeled amount of this compound in the formulation). Likewise, $500 \mu \mathrm{L}$ of syrup was diluted in DMSO to obtain a solution with a concentration of approximately $2 \mathrm{mg} / \mathrm{mL}$. All solutions were stored at $5^{\circ} \mathrm{C}$ and then filtered, prior to the use, through $0.45 \mu \mathrm{m}$ pore size disposable nylon filters from Titan (Eatontown, NJ, USA).

\section{3. $C E-U V$ instrument}

An HP $^{3 \mathrm{D}} \mathrm{CE}$ system (Hewlett-Packard, Waldbronn, Germany) equipped with an on-column diode array detector (DAD) for UV detection was employed in this work. A 3D-CE ChemStation software from Agilent Technologies was used for instrument control and data acquisition. Separations were performed using uncoated fused-silica capillaries of $50 \mu \mathrm{m}$ I.D. and $375 \mu \mathrm{m}$ O.D. with a UV detection length of $70 \mathrm{~cm}$ and a total length of $78.5 \mathrm{~cm}$, which were purchased from Composite Metal Services (Worcester, England). Before first use, uncoated capillaries were conditioned in the following way: a $30 \mathrm{~min}$ rinse with $1 \mathrm{M}$ $\mathrm{NaOH}$ was followed by a water rinse for other 5 and 60-min with the buffer solution. Between injections, the capillary was con- ditioned with the BGE for $2 \mathrm{~min}$. The capillary temperature was $15^{\circ} \mathrm{C}$ and UV detection was performed at $200 \mathrm{~nm}$ with a bandwidth of $10 \mathrm{~nm}$ using a reference wavelength of $350 \mathrm{~nm}$ with a bandwidth of $100 \mathrm{~nm}$, and a response time of $0.1 \mathrm{~s}$. Injections were made by pressure, 50 mbar for $4 \mathrm{~s}$, and the applied voltage was $30 \mathrm{kV}$.

\subsection{CE-MS instrument}

The analyses were carried out in an $\mathrm{HP}^{3 \mathrm{D}} \mathrm{CE}$ instrument (Agilent Technologies, Palo Alto, CA, USA) equipped with an on-column DAD for UV detection, and coupled through an orthogonal electrospray interface (ESI, model G1607A from Agilent Technologies, Palo Alto, CA, USA) to an ion-trap mass spectrometer (model 1100 from Agilent Technologies, Palo Alto, CA, USA) for MS detection. MS control and data analysis were carried out using the LC/MSD Trap Software 5.2. Uncoated fused-silica capillaries of $50 \mu \mathrm{m}$ I.D. with a UV detection length of $20 \mathrm{~cm}$ and a MS detection length of $80 \mathrm{~cm}$ were used. Injections were made by pressure, $50 \mathrm{mbar}$ for $4 \mathrm{~s}$, and the applied voltage was $20 \mathrm{kV}$. In this instrument the capillary was conditioned with the BGE for 4 min between injections.

Electrical contact at the electrospray needle tip was established using a sheath-liquid based on isopropanol:water (50:50, $\mathrm{v}: \mathrm{v})$ and delivered at a flow rate of $3.3 \mu \mathrm{L} / \mathrm{min}$ by a SGE Syringe, $10 \mathrm{~mL}$, Luer Lock from Supelco (Bellefonte, PA, USA). The mass spectrometer was operated in the positive ion mode $(4.5 \mathrm{kV})$. The spectrometer was scanned at $250-750 \mathrm{~m} / \mathrm{z}$ range. MS operating conditions were optimized. The nebulizer pressure and flow and the drying gas temperature were: 2 psi $\mathrm{N}_{2}$, and $4 \mathrm{~L} / \mathrm{min} \mathrm{N}_{2}$ at $250{ }^{\circ} \mathrm{C}$.

\section{Results and discussion}

\subsection{Detection of impurities in cis-ketoconazole by $C E-U V$}

According to the European Pharmacopoeia [16], four impurities are possible in $c i s$-ketoconazole as raw material. In order to detect the impurities of cis-ketoconazole and to investigate their chiral nature, a $0.4 \mathrm{M}$ formate buffer at $\mathrm{pH} 3.0$ was used with increasing concentrations of TM- $\beta-C D$ as chiral selector. TM- $\beta-C D$ was employed as chiral selector because in a previous work, this neutral $\beta-\mathrm{CD}$ was shown to be the best chiral selector for the enantiomeric separation of cis-ketoconazole [15], a compound structurally similar to its impurities. Fig. 2 shows the electropherograms obtained for a cis-ketoconazole standard solution under the above-mentioned experimental conditions. As it can be observed, in absence of the chiral selector only a peak was detected, which is well separated from the main compound (cis-ketoconazole). Therefore, only a major impurity seems to be detected under these conditions. On the other hand, it is interesting to observe that this major impurity is a racemic mixture (1:1 mixture of two enantiomers) that can be separated from the main compound ( is-ketoconazole) and enantiomerically resolved in the presence of TM- $\beta-C D$. In fact, baseline resolution of the enantiomers of the impurity was observed with TM- $\beta-C D$ concentrations higher than $2 \mathrm{mM}$ (see 


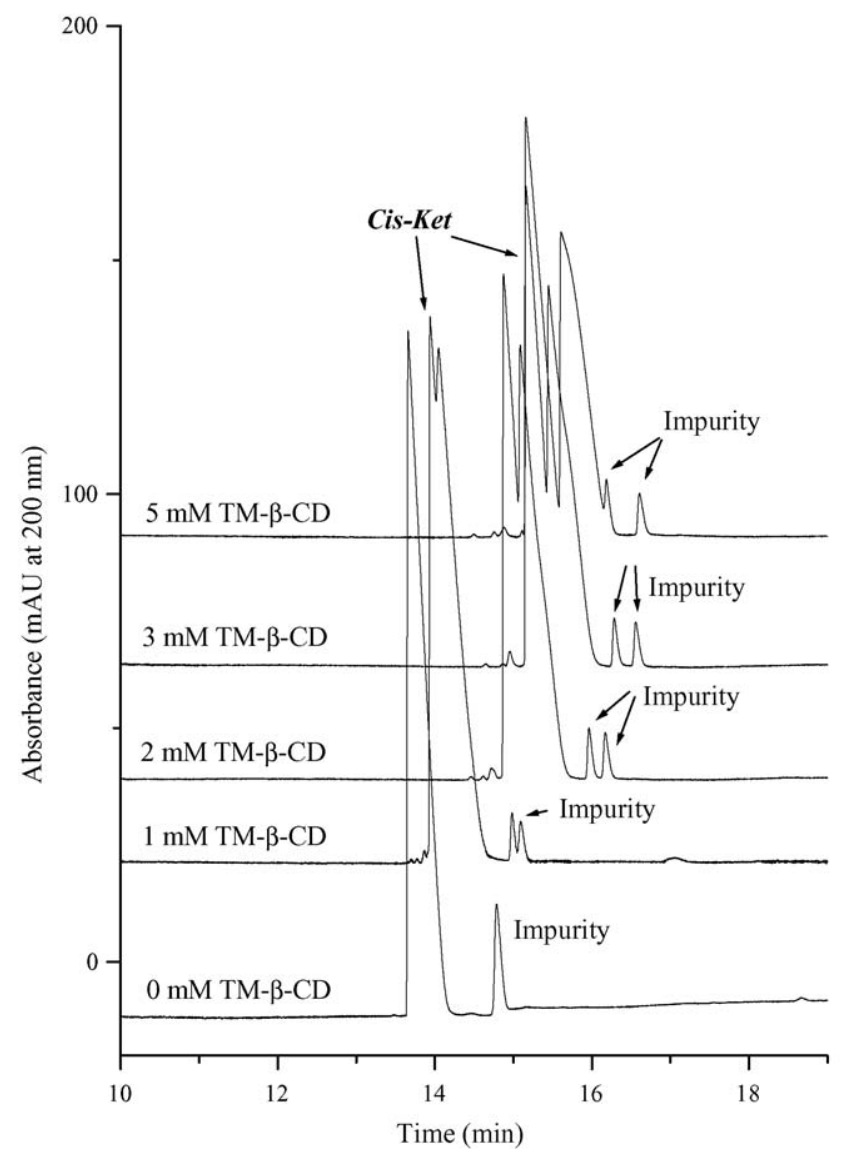

Fig. 2. Electropherograms corresponding to a cis-ketoconazole standard solution $(2 \mathrm{mg} / \mathrm{mL}$ in DMSO) in $0.4 \mathrm{M}$ formate buffer at $\mathrm{pH} 3.0$ with increasing concentrations of heptakis-(2,3,6-tri- $O$-methyl)- $\beta$-CD. Experimental conditions: untreated fused-silica capillary, $78.5 \mathrm{~cm}(70 \mathrm{~cm}$ to the detector window $)$ $\times 50 \mu \mathrm{m}$ I.D.; separation temperature, $15^{\circ} \mathrm{C}$; applied voltage, $30 \mathrm{kV}$; injection, $50 \mathrm{mbar} \times 4 \mathrm{~s}$; detection at $200 \pm 5 \mathrm{~nm}$ with reference at $350 \pm 50 \mathrm{~nm}$. Cis-ket: cis-ketoconazole.

Fig. 2). Although the enantioresolution increased at a TM- $\beta$ $\mathrm{CD}$ concentration of $5 \mathrm{mM}$, the first-migrating enantiomer of the racemic impurity comigrated with the cis-ketoconazole (see Fig. 2), i.e., the separation between the main compound and its major impurity was not complete under these conditions. At $10 \mathrm{mM}$ TM- $\beta$-CD only one enantiomer from the racemic impurity was observed (data not shown).

These results indicated that the impurity of cis-ketoconazole was a chiral substance, which could be separated from cis-ketoconazole under achiral conditions because the cisketoconazole and its impurity have different electrophoretic mobilities. However, this impurity could be trans-ketoconazole (geometrical isomer) or one of the other three chiral impurities reported by the European Pharmacopoeia [16].

An estimation of the percentage of impurity detected for cis-ketoconazole was performed by CE with UV detection under achiral conditions obtaining a value close to $2 \%$. This value is above the thresholds established by the $\mathrm{ICH}$ guidelines for impurities that must be identified or qualified for registered pharmaceuticals for human use [1-3]. As there were no commercially available standards for the four possible impurities of cis-ketoconazole, a probable identifica- tion by $\mathrm{CE}$ with UV detection was not possible. Therefore, CE-ESI-MS was employed for the identification of this impurity in cis-ketoconazole because the possible impurities reported in the European Pharmacopoeia [16] have different masses (trans-ketoconazole of exact $\operatorname{mass}=530.1487 \mathrm{~g} / \mathrm{mol}$; impurity II of exact mass $=528.1331 \mathrm{~g} / \mathrm{mol}$; impurity III of exact mass $=720.2481 \mathrm{~g} / \mathrm{mol}$ and impurity IV of exact mass $=488.1382 \mathrm{~g} / \mathrm{mol}$ ). In order to obtain a limit of detection (LOD) as low as possible, the volatile BGE was used under achiral conditions because the presence of non-volatile components (e.g., cyclodextrins) in the BGE decreases the sensitivity, increases the background noise and can clog the system [18-20]. In addition, under achiral conditions, only one peak was observed for the impurity, providing a better sensitivity than that obtained for the two peaks observed under chiral conditions.

\subsection{Identification of cis-ketoconazole impurity by CE-ESI-MS}

Using formate buffer at pH 3.0 as BGE for the separation of cis-ketoconazole and its impurity in the format of capillary zone electrophoresis (CZE), several analytical parameters affecting ESI-MS sensitivity were studied.

Firstly, different sheath-liquid compositions and flows were tested in order to increase MS signal. Fig. 3a shows the relative intensity obtained for $c i s$-ketoconazole, calculated from the extracted ion electropherogram (EIE) at $531 \pm 0.5 \mathrm{~m} / \mathrm{z}$, for different percentages $(0-0.5 \%)$ of formic acid in isopropanol:water $(50: 50, \mathrm{v}: \mathrm{v})$. It can be observed that a sheath-liquid composed of isopropanol:water $(50: 50, \mathrm{v}: \mathrm{v})$ without formic acid provided the best relative intensities. This result can be explained considering that the high concentration of formic acid in the BGE is probably enough to obtain a good ionization of the analytes at the interface and an adequate electrical contact. Other organic solvents (methanol or acetonitrile) and acetic acid (0-0.5\%) instead of formic acid were also tested but worse relative intensities were obtained in all cases (results not shown).

Next step was to study the influence of the sheath-liquid flow on the MS relative intensities of cis-ketoconazole when isopropanol:water (50:50, v:v) was used. From the different sheath-liquid flows studied $(1.7-6.7 \mu \mathrm{L} / \mathrm{min})$, a flow of $3.3 \mu \mathrm{L} / \mathrm{min}$ provided the highest relative intensities although similar values were also obtained for flows of 5.0 and $6.7 \mu \mathrm{L} / \mathrm{min}$ (see Fig. 3b). Under these sheath-liquid conditions, the effect of several other ESI parameters (drying temperature, sampling capillary potential and drying gas flow) was investigated. Four drying temperatures $\left(200,250,300\right.$ and $\left.350{ }^{\circ} \mathrm{C}\right)$ were tested observing that $250{ }^{\circ} \mathrm{C}$ provided the highest relative intensity (see Fig. 3c) although this parameter had little influence. Four different potentials were applied in the sampling capillary observing the best sensitivity for $4.5 \mathrm{kV}$ (see Fig. 3d). Finally, the drying gas flow was then studied testing values of $2,3,4,5$ and $6 \mathrm{~L} / \mathrm{min}$ obtaining the highest relative intensity with $4 \mathrm{~L} / \mathrm{min}$ (see Fig. 3e). In addition, although the resolution between $\mathrm{cis}$-ketoconazole and its impurity decreased (from 5.4 to 3.9) with the increment of the drying gas flow a good resolution (4.9) was observed at $4 \mathrm{~L} / \mathrm{min}$. 

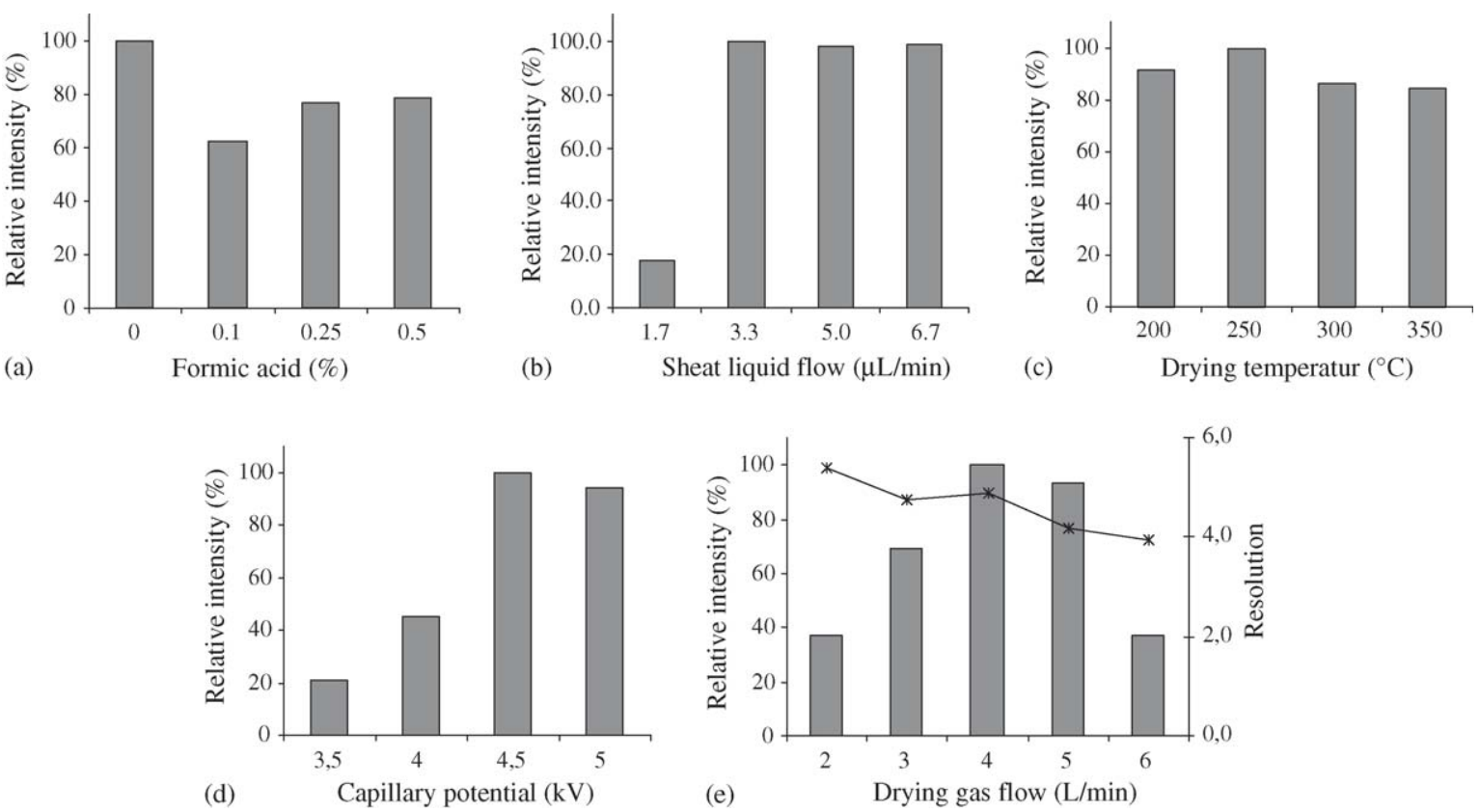

Fig. 3. Bar diagrams showing the relative intensity obtained for the peak of cis-ketoconazole in the EIE at $531 \pm 0.5 \mathrm{~m} / \mathrm{z}$ with: (a) different percentages of formic acid in a sheath-liquid of isopropanol:water (50:50, v:v) with a flow of $3.3 \mu \mathrm{L} / \mathrm{min}$ using $2 \mathrm{psi}$ for the nebulizer pressure, $350^{\circ} \mathrm{C}$ and $4 \mathrm{~L} / \mathrm{min}$ for the drying gas, and $4.5 \mathrm{kV}$ in the sampling capillary; (b) different flow rates for a sheath-liquid of isopropanol:water (50:50, v:v) using other conditions as (a); (c) different drying temperatures using other conditions as (b); (d) different potentials in the sampling capillary using a drying temperature of $250^{\circ} \mathrm{C}$, and other conditions as (b) and (e) different drying gas flow rates using other conditions as (d). CE conditions: untreated fused-silica capillary, $80 \mathrm{~cm} \times 50 \mu \mathrm{m} \mathrm{I.D.;} \mathrm{applied} \mathrm{voltage,} 20 \mathrm{kV}$; other conditions as in Fig. 2.

The selected CE-ESI-MS conditions with a scan between 250 and $750 \mathrm{~m} / \mathrm{z}$ were used to analyze different samples containing cis-ketoconazole. Namely, one commercial standard formulation, and three pharmaceutical formulations, two tablets and one syrup, were analyzed. Mass spectra were obtained for cis-ketoconazole and its impurity in all samples observing that these spectra were practically identical for all samples analyzed (see Fig. 4), i.e., the mass spectra had the same value of $\mathrm{m} / \mathrm{z}$ for the protonated molecular ion, and their isotopic distributions had very similar relative intensities, which are characteristics of molecules with two chlorine atoms. Among the possible impurities reported in the European Pharmacopeoiea [16] (impurity I corresponding to trans-ketoconazole of exact mass $=530.1487 \mathrm{~g} / \mathrm{mol}$; impurity II of exact mass $=528.1331 \mathrm{~g} / \mathrm{mol}$; impurity III of exact mass $=720.2481 \mathrm{~g} / \mathrm{mol}$ and impurity IV of exact mass $=488.1382 \mathrm{~g} / \mathrm{mol}$ ), only trans -ketoconozale has the same value of $\mathrm{m} / \mathrm{z}$ for the protonated molecular ion as cisketoconazole; therefore, the impurity detected for cisketoconazole was identified as the trans-isomer of ketoconazole.

\subsection{Quantitation of trans-ketoconazole in cis-ketoconazole by $C E-E S I-M S$}

Prior to the quantitation of the impurity in the different analyzed samples, a comparative study on the quantitative capabilities of CE-UV and CE-MS analysis of ketoconazole was simultaneously carried out by using the CE-MS instrument, as this system also allowed UV-detection at $20 \mathrm{~cm}$ of the inlet position (see Section 2). In order to improve MS sensitivity for the impurity, fragmentation of the $531 \mathrm{~m} / \mathrm{z}$ parent ion was investigated under MS/MS conditions. However, in comparison with that of the parent ion, no intensity improvement was observed with the fragments, and therefore single MS analysis was selected for the rest of the experiments. Then, an $\mathrm{m} / \mathrm{z}$ window for the EIE between 531.0 and $0.5 \mathrm{~m} / \mathrm{z}$ and $531.0+4.5 \mathrm{~m} / \mathrm{z}$ was selected according to the isotopic distribution (from 531 to 535, see Fig. 4) because the highest intensity of ions and the best signal-to-noise ratio were obtained under these conditions.

The figures of merit obtained for CE-UV and CE-MS are summarized in Table 1. As it can be seen, CE-UV provides faster analysis times than CE-MS as could be expected from the smaller length of the capillary needed for CE-UV detection in the CE-MS instrument $(20 \mathrm{~cm}$ versus $80 \mathrm{~cm})$. The other figures of merit evaluated were linearity, sensitivity and repeatability. As trans-ketoconazole standard (impurity) was not available, these parameters were evaluated by injecting the cis-ketoconazole standard (main compound) in the CE system with UV and MS detection.

Linearity was established by injecting by triplicate eight solutions of $c i s$-ketoconazole with concentrations ranging from 0.02 to $2.00 \mathrm{mg} / \mathrm{mL}$ (see Section 2.2). It was observed that the signal measured for the main compound by UV and MS detection correlated linearly along this range of concentrations. The range of concentrations for the impurity calculated as the main compound concentration multiplied by 0.021 for UV detection and 0.024 for MS detection (see the percentage of impurity calculated for the cis-ketoconazole standard in Table 2) is also shown in Table 1. In all cases, good correlation coefficients $(>0.99)$ were obtained. 


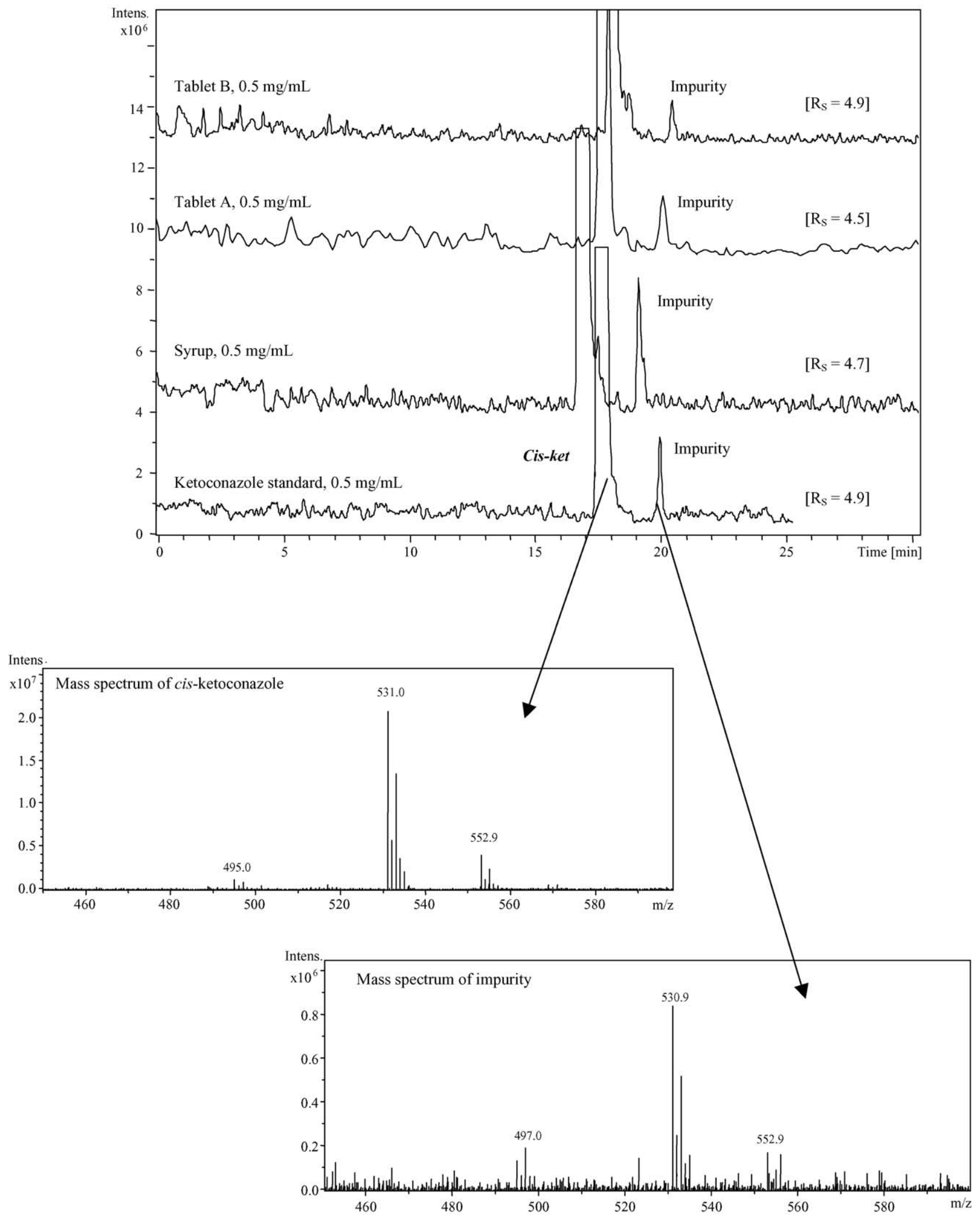

Fig. 4. Extracted ion electropherograms (from $531.0-0.5$ to $531.0+4.5 \mathrm{~m} / \mathrm{z}$ ) for a cis-ketoconazole standard, a syrup, and two tablets (A and B) showing the mass spectra for the standard. Resolution values obtained for cis-ketoconazole and its impurity are included in brackets. CE conditions as in Fig. 3. ESI-MS conditions: positive ion mode, sampling capillary voltage, $4.5 \mathrm{kV}$; drying gas flow, $4 \mathrm{~L} / \mathrm{min}$; drying temperature, $250^{\circ} \mathrm{C}$; nebulizer pressure, 2 psi; sheath-liquid, isopropanol:water (50:50, v:v) at $3.3 \mu \mathrm{L} / \mathrm{min}$; mass scan: $250-750 \mathrm{~m} / \mathrm{z}$. 
Table 1

Performance parameters for analysis of ketoconazole by CE-UV and CE-ESI-MS

\begin{tabular}{|c|c|c|c|c|}
\hline \multirow[t]{2}{*}{ Parameter } & \multicolumn{2}{|l|}{ CE-UV } & \multicolumn{2}{|l|}{ CE-MS } \\
\hline & Main compound & Impurity & Main compound & Impurity \\
\hline Analysis time (min) & 4.4 & 6.8 & 17.3 & 19.7 \\
\hline Concentration range $(\mathrm{mg} / \mathrm{mL})$ & $0.02-2.00$ & $0.0042-0.042$ & $0.02-2.00$ & $0.0048-0.048$ \\
\hline Linear equation & $y=6.06+657.05 x$ & $y=-5.32+1221.30 x$ & $y=7.51 \times 10^{5}+8.15 \times 10^{7} x$ & $y=-3.85 \times 10^{5}+2.54 \times 10^{8} x$ \\
\hline Standard errors ${ }^{\mathrm{b}}$ & $s_{\mathrm{a}}=6.75 \mathrm{~s} \mathrm{~b}=6.95$ & $s_{\mathrm{a}}=2.41 s_{\mathrm{b}}=93.47$ & $\mathrm{~s}_{\mathrm{a}}=1.48 \times 10^{6} \mathrm{~s}_{\mathrm{b}}=1.43 \times 10^{6}$ & $s_{\mathrm{a}}=3.94 \times 10^{5} s_{\mathrm{b}}=1.34 \times 10^{7}$ \\
\hline LOD $(\mathrm{mg} / \mathrm{L} \text { or } \%)^{\mathrm{d}}$ & 0.03 & $0.3 \%$ & 0.05 & $0.2 \%$ \\
\hline $\operatorname{LOQ}(\mathrm{mg} / \mathrm{L} \text { or } \%)^{\mathrm{d}}$ & 0.10 & $1.0 \%$ & 0.18 & $0.8 \%$ \\
\hline \multicolumn{5}{|l|}{ Repeatability $(\mathrm{RSD} \%)^{\mathrm{e}}$} \\
\hline Migration time & 2.7 & 2.9 & 1.1 & 1.0 \\
\hline Corrected peak area & 2.8 & 11.9 & 29.6 & 29.5 \\
\hline
\end{tabular}

${ }^{a}$ Eight standard solutions were injected by triplicate within the same day.

b Standard errors of the intercept $\left(s_{\mathrm{a}}\right)$, and of the slope $\left(s_{\mathrm{b}}\right)$.

${ }^{c}$ Values calculated from the study of linearity: LOD, $3 s_{\mathrm{a}} / \mathrm{b}$, and LOQ, $10 s_{\mathrm{a}} / \mathrm{b}$, where $s_{\mathrm{a}}$ is the standard error of the intercept, and $\mathrm{b}$ is the slope of the calibration curve [21].

${ }^{\mathrm{d}}$ Values of LOD and LOQ in $\mathrm{mg} / \mathrm{L}$ for the main compound and in $\%$ for the impurity (referred to $2.00 \mathrm{mg} / \mathrm{mL}$ of main compound).

${ }^{\mathrm{e}} \mathrm{RSD}(\%)$ was calculated from five injections within the same day of a ketoconazole standard solution $(0.5 \mathrm{mg} / \mathrm{mL})$.

Sensitivity was evaluated by calculating the LOD and limit of quantitation (LOQ) for the main compound and its impurity. LOD and LOQ calculated by using a signal-to-noise ratio of 3 and 10, respectively, are reported in Table 1. The main compound can be detected at $0.03 \mathrm{mg} / \mathrm{mL}$ and quantified at $0.10 \mathrm{mg} / \mathrm{mL}$ by UV detection. However, with MS detection slightly higher concentrations can be detected $(0.05 \mathrm{mg} / \mathrm{mL})$ and quantified $(0.18 \mathrm{mg} / \mathrm{mL})$. The percentages of impurity that have been detected and quantified are about 0.3 and $0.9 \%$ by UV and MS detection, respectively.

Repeatability was determined in order to establish the intraday variation in migration times and corrected peak areas. The relative standard deviation expressed in percentage (RSD\%) was calculated from the data obtained for five runs performed on the same day and obtained by injecting the main compound at a concentration of $0.5 \mathrm{mg} / \mathrm{mL}$. RSD percentages lower than $2.9 \%$ were obtained for migration times when UV detection was used and lower than $1.1 \%$ for MS detection. Nevertheless, RSD values obtained for corrected peak areas were much worse for MS detection than for UV detection. Although these values seem to be very high (see Table 1), similar values have been reported in other works on CE-MS published recently [22].

Table 2

Comparison of the percentage of impurity (expressed as average \pm standard deviation) in the different samples determined by CE-UV and CE-ESI-MS $(n=3)$, and t-test to compare the means of the two methods

\begin{tabular}{llll}
\hline Sample & $\begin{array}{l}\text { CE-UV } \\
\% \text { impurity }\end{array}$ & $\begin{array}{l}\text { CE-MS } \\
\% \text { impurity }\end{array}$ & $\begin{array}{l}t \text {-test } \\
p \text {-value }\end{array}$ \\
\hline cis-Ketoconazole standard & $2.1 \pm 0.2$ & $2.4 \pm 0.6$ & 0.54 \\
Syrup & $2.7 \pm 0.6$ & $4.0 \pm 0.5$ & 0.052 \\
Tablet A & $3.2 \pm 0.3$ & $3.3 \pm 0.4$ & 0.78 \\
Tablet B & $2.5 \pm 0.3$ & $3.0 \pm 0.1$ & 0.067 \\
\hline
\end{tabular}

Finally, the quantitation of the impurity in the different samples analyzed was performed. Table 2 shows the percentages obtained for the impurity of cis-ketoconazole (trans-ketoconazole) (calculated as $A_{\text {impurity }} \times 100 / A_{\text {total }}$, where $A_{\text {impurity }}$ corresponds to the corrected peak area of transketoconazole and $A_{\text {total }}$ to the total corrected area, i.e., the sum of the two peak areas corresponding to cis-ketoconazole and transketoconazole). A $2.1 \%$ of the impurity was determined for the standard of cis-ketoconazole when CE-UV was used, whereas $2.4 \%$ of impurity was determined by CE-MS. For the three pharmaceutical formulations studied, percentages of impurity ranging from 2.7 to $3.2 \%$ were determined with UV detection and from 3.0 to $4.0 \%$ with MS detection. However, the $t$-test showed that there were no statistically significant differences between the values obtained by the two methods at $95.0 \%$ confidence level ( $p$-values between 0.052 and 0.78 were obtained).

Due to the fact that percentages of the cis-ketoconazole impurity determined were higher than $2.0 \%$ in all cases, the identification and quantitation according to the ICH guidelines should be carried out. This fact shows the high interest of the development of a CE-ESI-MS method for the identification and quantitation of cis-ketoconazole impurity in standard samples and pharmaceutical formulations successfully performed in this work.

\section{Concluding remarks}

The impurity of cis-ketoconazole, a chiral antifungal, has been detected and identified by CZE-ESI-MS using $0.4 \mathrm{M}$ ammonium formate at $\mathrm{pH} 3.0$ as separation buffer. Under optimum CE-MS conditions, trans-ketoconazole could be identified as the impurity of cis-ketoconazole. As this impurity is a diastereomer of the antifungal agent studied and has the same $\mathrm{m} / \mathrm{z}$ value, its previous separation by $\mathrm{CE}$ is necessary for its unequivocal identification. In addition, the quantitation of this impurity 
in different samples ( $c$ is-ketoconazole standard and three different pharmaceutical formulations: two tablets and one syrup) has also been achieved. Impurity contents higher than $2.0 \%$ were determined in all cases.

\section{Acknowledgements}

Authors thank the Ministry of Science and Technology (Spain) for the research project BQU2003-03638. Carmen García-Ruiz thanks the Ministry of Science and Technology for the Ramón y Cajal program (RYC-2003-001). María CastroPuyana thanks the University of Alcalá for her pre-doctoral grant.

\section{References}

[1] International Conference on Harmonization. ICH Harmonized Tripartite Guidelines. Q3A(R): Impurities in New Drug Substances. Published in the Federal Register, vol. 68, No. 68, 2003, pp. 6924-6925.

[2] International Conference on Harmonization. ICH Harmonized Tripartite Guidelines. Q3B(R): Impurities in New Drug Products. Published in the Federal Register, vol. 68, No. 220, 2003; pp. 64628-64629.

[3] International Conference on Harmonization. ICH Harmonized Tripartite Guidelines. Quality topics: Q3 Impurity Testing. <http://www.ich.org/ cache/compo/276-254-1.html> [Checked on January 2006].

[4] I. Toro, J.F. Dulsat, J.L. Fábregas, J. Claramunt, J. Chromatogr. A 1043 (2004) 303.
[5] T.K. Natishan, J. Liq. Chromatogr. R. T. 28 (2005) 1115.

[6] C.C. Lin, Y.T. Li, S.H. Chen, Electrophoresis 24 (2003) 4106.

[7] W.C. Sung, S.H. Chen, Electrophoresis 22 (2001) 4244.

[8] G. Guetens, G. De Boeck, M.S. Highley, M. Wood, R.A.A. Maes, A.A.M. Eggermont, A. Hanauske, E.A. de Bruijn, U.R. Tjaden, J. Chromatogr. A 976 (2002) 239.

[9] J.C. Severs, R.D. Smith, in: R.B. Cole (Ed.), Electrospray Ionization Mass Spectrometry, Fundamentals, Instrumentation and Applications, Wiley, New York, 1997, p. 343.

[10] P. Schmitt-Kopplin, M. Frommberger, Electrophoresis 24 (2003) 3837.

[11] J. Hernández-Borges, C. Neusüß, A. Cifuentes, M. Pelzing, Electrophoresis 25 (2004) 2257.

[12] C. Simó, C. Barbas, A. Cifuentes, Electrophoresis 26 (2005) 1306.

[13] W.F. Smyth, Electrophoresis 26 (2005) 1334.

[14] W.F. Smyth, P. Brooks, Electrophoresis 25 (2004) 1413.

[15] M. Castro-Puyana, A.L. Crego, M.L. Marina, Electrophoresis 26 (2005) 3960.

[16] European Pharmacopoeia, 4th ed., 2002.

[17] Y.L. Chen, L. Felder, X. Jiang, W. Naidong, J. Chromatogr. B 774 (2002) 67.

[18] G.A. Ross, LC-GC Eur. 1 (2001) 2.

[19] R.D. Smith, J.H. Wahl, D.R. Goodlett, S.A. Hofstadler, Anal. Chem. 65 (1993) 574.

[20] W.M.A. Niessen, U.R. Tjaden, J. Van der Greef, J. Chromatogr. 636 (1993) 3.

[21] L.L.A. Currie, Pure Appl. Chem. 67 (1995) 1699.

[22] M. Arias, C. Simó, L.T. Ortiz, M. de los Mozos-Pascual, C. Barbas, A. Cifuentes, Electrophoresis 26 (2005) 2351. 